\title{
Modulation of the acetylcholine-catecholamine balance in the cognitive processes and its correlations with the oxidative stress Alin Ciobica*1, Manuela Padurariu ${ }^{2}$, Lucian Hritcu ${ }^{1}$ and Vlad Artenie ${ }^{1}$
}

\author{
Address: ${ }^{1}$ Alexandru Ioan Cuza, University, Dept. of Molecular and Experimental Biology, Iasi, Romania and ${ }^{2}$ Gr. T. Popa, University of Medicine \\ and Pharmacy, Iasi, Romania \\ * Corresponding author
}

\author{
from International Society on Brain and Behaviour: 3rd International Congress on Brain and Behaviour \\ Thessaloniki, Greece. 28 November - 2 December 2007 \\ Published: 17 April 2008 \\ Annals of General Psychiatry 2008, 7(Suppl I):S348 doi:I0.1 I86/I744-859X-7-SI-S348
}

This abstract is available from: http://www.annals-general-psychiatry.com/content/7/SI/S348

(c) 2008 Ciobica et al.; licensee BioMed Central Ltd.

\section{Background}

Impairments of cognitive performance have been observed our previous studies in normal rats with muscarinic acethylcholine receptors (mAchRS), beta-adrenergic receptors ( $\beta$ AR) and D2-dopamine receptors (D2R) blockade, suggesting that these receptors have a facilitator role in learning and memory processes. Learning and memory processes are coordinated with different brain regions [1]. Since the oxidative damage may play a role in the aging process [2], including the associated decline, age-related impairment in spatial learning and memory may be alleviated by antioxidant treatment [3].

\section{Materials and methods}

Learning and memory tasks : Y-maze task; Step-through passive avoidance task.

Biochemical estimation : Determination of superoxid dismutaze (SOD), Determination of glutathione peroxidase (GPX), Determination of malondialdehyde (MDA).

\section{Results}

We observed that the levels of superoxide dismutase (SOD) and glutathione peroxidase (GPX) decrease in rats with mAchRS, D2R and $\beta$ AR blockade by means of scopolamine $(0.75 \mathrm{mg} / \mathrm{kg}$ b.w., i.p.), spiperone $(0.4 \mathrm{mg} / \mathrm{kg}$ b.w.,i.p.) and propranolol (12 mg/kg b.w., i.p.), respectively, and the level of malondialdehyde (MDA) increase in the same rats, compared with saline-treated rats.

\section{Conclusions}

Muscarinic cholinergic and dopaminergic systems have a facilitating effect on mechanism that operates during the storage of information as memory engrams. We demonstrated that the increased oxidative stress is followed by cognition impairment in rats. Our findings support the hypothesis that oxidative stress plays a crucial role in brain dysfunction, contributing to the learning and memory deficits in rats.

\section{Acknowledgements}

This research was supported by the National Council of Scientific Research and University Education (Grant TD CNCSIS no. 464), Romania.

\section{References}

I. Ekstrom AD, Bookheimer SY: Spatial and temporal episodic memory retrieval recruit dissociable functional networks in the human brain. Learn Mem 2007, 14:645-654.

2. Flora SJ: Role of free radicals and antioxidants in health and disease. Cell Mol Biol 2007, 53:I-2.

3. Barichello T, Machado RA, Constantino Valvassori L: Antioxidant treatment prevented late memory impairment. Crit Care Med 2007, 35:2186-2190. 